\title{
Diesel Combustion: An Integrated View Combining Laser Diagnostics, Chemical Kinetics, and Empirical Validation
}

\author{
Patrick F. Flynn \\ Russell P. Durrett \\ Gary L. Hunter \\ Axel O. zur Loye \\ O.C. Akinyemi \\ John E. Dec \\ Charles K. Westbrook
}

This paper was prepared for submittal to the

1999 Society of Automotive Engineers

International Congress and Exposition

Detroit, MI

March 1-4, 1999

February 1999

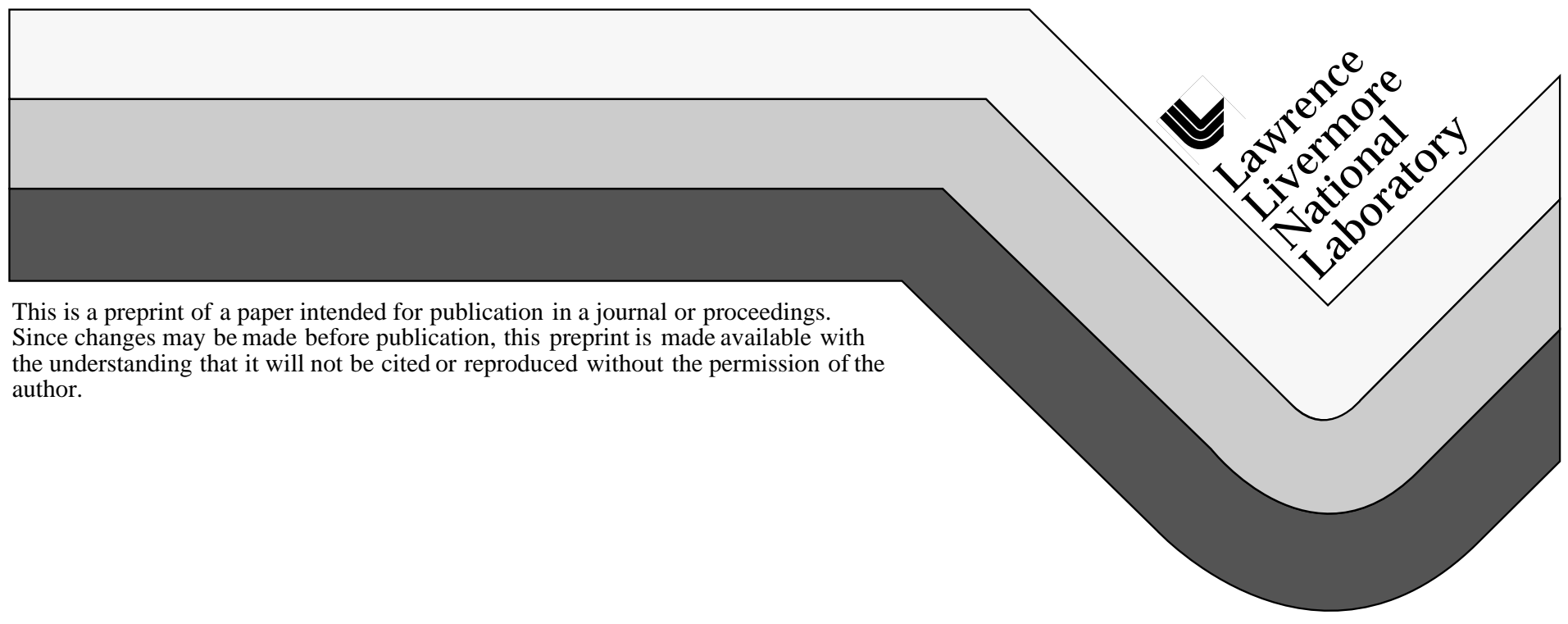




\section{DISCLAIMER}

This document was prepared as an account of work sponsored by an agency of the United States Government. Neither the United States Government nor the University of California nor any of their employees, makes any warranty, express or implied, or assumes any legal liability or responsibility for the accuracy, completeness, or usefulness of any information, apparatus, product, or process

disclosed, or represents that its use would not infringe privately owned rights. Reference herein to any specific commercial product, process, or service by trade name, trademark, manufacturer, or otherwise, does not necessarily constitute or imply its endorsement, recommendation, or favoring by the United States Government or the University of California. The views and opinions of authors expressed herein do not necessarily state or reflect those of the United States Government or the University of California, and shall not be used for advertising or product endorsement purposes. 


\title{
Diesel Combustion: An Integrated View Combining Laser Diagnostics, Chemical Kinetics, And Empirical Validation
}

\author{
Patrick F. Flynn, Russell P. Durrett, Gary L. Hunter, Axel O. zur Loye, and O. C. Akinyemi \\ Cummins Engine Company
}

Sandia National Laboratories, Combustion Research Facility

Charles K. Westbrook

Lawrence Livermore National Laboratory

\begin{abstract}
This paper proposes a structure for the diesel combustion process based on a combination of previously published and new results. Processes are analyzed with proven chemical kinetic models and validated with data from production-like direct injection diesel engines. The analysis provides new insight into the ignition and particulate formation processes, which combined with laser diagnostics, delineates the twostage nature of combustion in diesel engines. Data are presented to quantify events occurring during the ignition and initial combustion processes that form soot precursors. A framework is also proposed for understanding the heat release and emission formation processes.
\end{abstract}

\section{INTRODUCTION}

Significant progress has been made recently in furthering our understanding of the nature of the diesel combustion process. This progress, along with improvements in widely available computational capabilities, makes it possible for a broader range of organizations to work on the quantitative validation of the processes taking place within the diesel engine. Government laboratories in the U.S., Europe and several universities (1-20) have undertaken laser imaging studies to define the structure of diesel flames and their temporal evolution. Although these diagnostics were performed on a variety of engine and high-pressure vessel configurations, they show many similarities and begin to form a basis for the general description of a burning diesel fuel spray plume.

At the same time these images of diesel flame structure were obtained, researchers and modelers focusing on chemical kinetics created models that included appropriate combinations of reaction species and quantified reaction pathways. This made kinetic models valuable tools for tracking the processes in reacting fuel/air mixtures. These efforts (21-23) have been made at government laboratories and universities. Until recently, engineers have found it difficult to obtain the computational power to exercise these models on anything except the simplest of hypothetical processes. Improvements in computational speed and reductions in the cost of memory have made the utilization of these programs on more complicated problems plausible by researchers in industry.

Presently, the integration of these large-scale chemistry models with $3 D$ viscous fluid mechanics models of fuel spray and in-cylinder air motion is still beyond the capability of most industrial organizations. In the interim it is plausible to consider a sequence of piecewise analyses of the processes. The laser diagnostic data present an appropriate structure for ordering such incremental analyses.

Given the status of these tools, the authors chose to undertake a series of incremental analyses in which detailed chemical kinetic calculations were linked with the spatial and temporal descriptions defined by researchers in laser imaging experiments that are available in the open literature. The following sections of the paper present the understandings that arise from such analyses. In some instances it has been possible to draw specific quantitative conclusions about the processes, their history, and the mechanisms that might modify them. In other parts of the flame there is still a need to develop more detailed understandings. However, even where precise quantitative detail is lacking, it is possible to draw qualitative conclusions 
about the sequence of processes as they are driven by the reactions taking place inside the burning diesel fuel spray.

One of the aspects is pollutant formation. Precise calculations of particulate and NOx levels are beyond current capabilities. However, the current analytical approach can be used to speculate qualitatively about the formation of these pollutants. Accordingly, chemical kinetic analyses have been exercised over broad ranges of temperature, pressure, and fuel/air ratio. These analyses can be used to hypothesize about the particulate and NOx formation processes that have been proposed by laser diagnosticians. Although these calculations are approximate, we believe that the results are useful. It is our hope that this work will encourage other researchers to add detail to the picture of diesel combustion and emission formation processes.

Following this introduction a brief discussion of the laserimaging process is given. This is followed by discussions focusing on a comparison of the new picture of flame structure and previous descriptions of the diesel combustion process as implemented by modelers and researchers. Once the new understanding of flame structure has been presented, the paper focuses on the chemical analysis and methods used to quantify the extent of reaction, local heat release, and evolution of chemical species. Results from this piecewise modeling process appear to be in good agreement with images portrayed by laser diagnostics. Also, with the analysis of kinetics for the early portion of combustion, it becomes possible to draw a reasonably complete and quantitative picture of the processes of fuel injection, ignition, and initial oxidation reactions.

\section{LASER DIAGNOSTICS}

Researchers at the Sandia Combustion Research Facility in Livermore, California used laser-based planar imaging diagnostics to provide the detailed measurements needed to better understand the diesel combustion process. Over the past decade, a wide variety of these diagnostics have been applied to directinjection (DI) diesel combustion using a specially designed, optically accessible research engine (1-4,1319,24-26). These laser-imaging measurements have provided an abundance of new information about the details of diesel combustion and emissions formation.

The single-cylinder research engine used for these studies is based on a Cummins $\mathrm{N}$ Series production engine typical of the heavy-duty size class (2.34 liters/cylinder). This research engine retains the basic geometry of the production engine, but has been modified with windows in the combustion chamber to provide the required optical access (3).
The optical data obtained with this engine have included the following laser-sheet imaging measurements: Mie scattering to determine liquid-phase fuel distributions (13), Rayleigh scattering for quantitative vapor-phasefuel/air mixture images and temperature fields (15), laser-induced incandescence (LII) for relative soot concentrations $(2,3,24)$, simultaneous LII and Rayleigh scattering for relative soot particle-size distributions $(17,18)$, planar laser-induced fluorescence (PLIF) to obtain early $\mathrm{PAH}$ (poly-aromatic hydrocarbon) distributions (24), PLIF images of the $\mathrm{OH}$ radical that show the diffusion flame structure (4), and PLIF images of the NO radical showing the onset of NOx production (25). In addition, natural-emission chemiluminescence images were obtained to investigate autoignition, and natural soot luminosity images showed initial soot development and overall jet penetration $(3,18,26)$.

These imaging diagnostics have been used to map out the processes occurring in the cylinder of an operating diesel engine from the start of injection, through autoignition, the premixed reaction, and the first part of the mixing-controlled burn (i.e. until the end of injection). Although each diagnostic provides a measurement of a specific aspect of the reacting diesel fuel jet, many of the experimental results are inter-related through the combustion physics. As a result, measurements from one type of diagnostic provide a crosscheck on measurements from another. In every case where multiple diagnostics provided information, there was good agreement between information from different experiments. For example, quantitative Rayleigh scatter imaging showed that vapor-fuel/air mixture during the premixed reaction is fuel-rich (equivalence ratio of 3 to 4). This mixture should be too rich to produce significant concentrations of $\mathrm{OH}$ or $\mathrm{NO}$, but it should produce soot. In agreement, the $\mathrm{OH}$ and NO PLIF images showed no signal from this rich reaction zone, but simultaneous LII and Rayleigh-scatter images showed small soot particles forming shortly after the onset of hot combustion reactions $(24,25)$.

\section{DIESEL FLAME STRUCTURE}

Prior to the information produced by laser-based imaging diagnostics, a variety of structures have been proposed to describe the nature of the combustion processes in diesel engines. One example is shown in Figure 1. This schematic is reproduced from Chiu (27). It is typical of the types of models developed by various researchers in the 1970s when computational capabilities limited the complexity of models that could be manipulated. This model proposed a diesel spray made of a dense fuel rich core surrounded by progressively leaner fuel/air mixtures reacting as air was entrained into the spray and oxygen was made available to react with the fuel. 


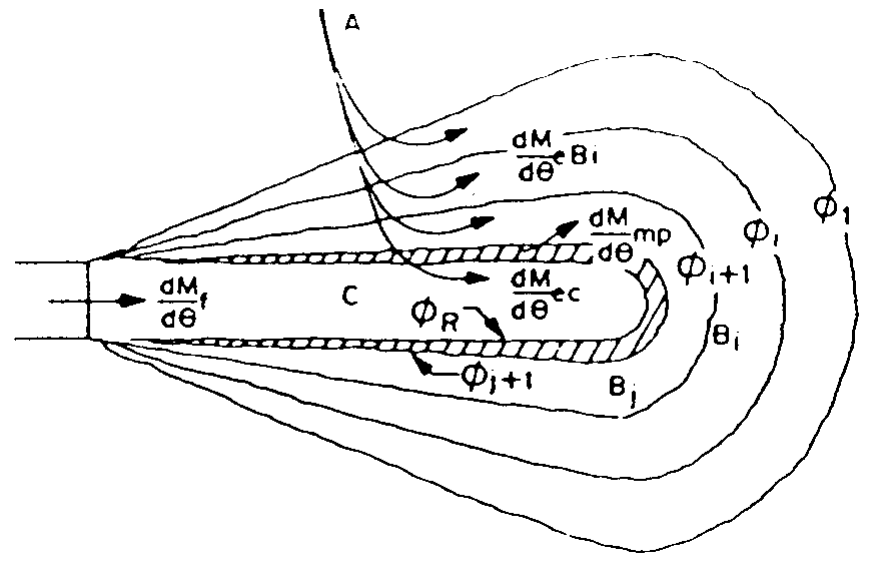

Figure 1 Early spray jet model
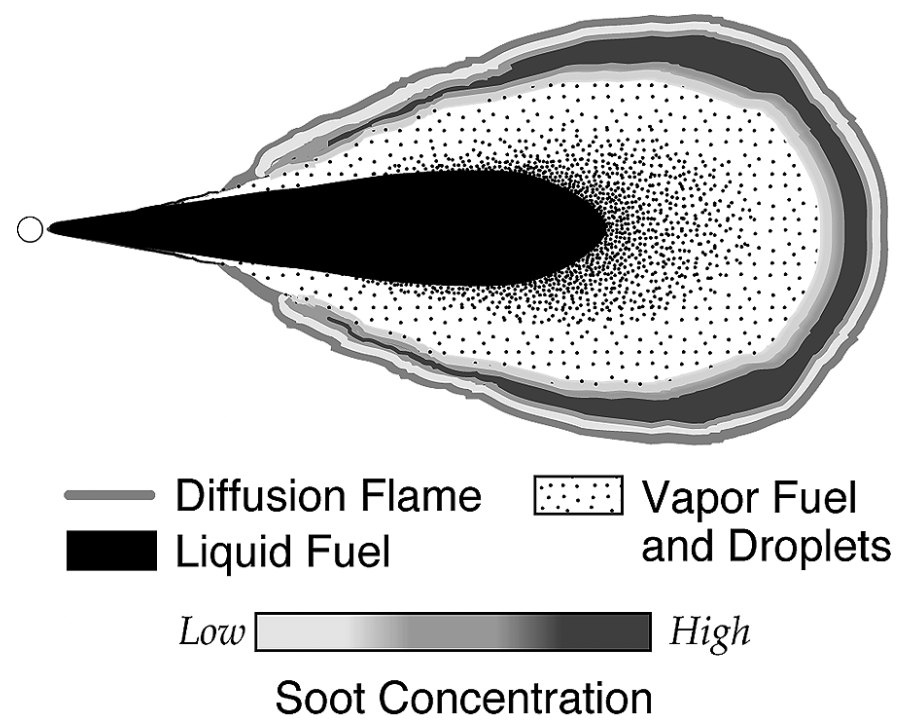

Figure 2 Recent spray model.

Over the years, other variations of the model for diesel spray combustion evolved. Figure 2 shows a 
These new conceptual images (Figures 3 and 4) provide a spatial definition of liquid disappearance and zones where reactions occur in the fuel-vapor/air mixture. Also visible are the regions where specific reaction intermediaries, such as $\mathrm{OH}$, are present that indicate the location of the vigorous diffusion burning processes. These images, along with the more detailed analysis presented by Siebers (11), allow the delineation of times and travel within this flame structure.
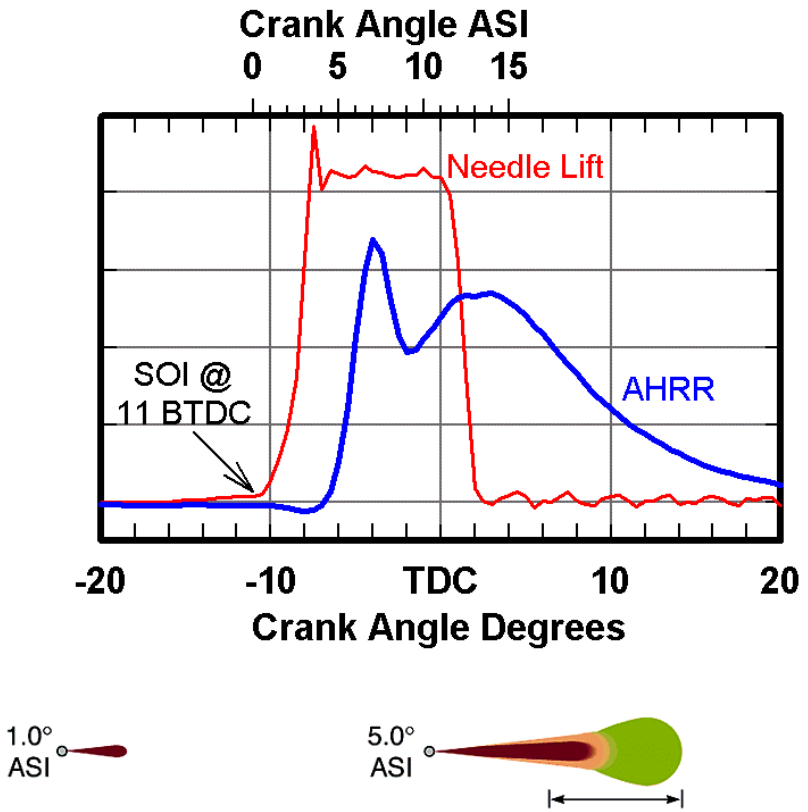

$2.0^{\circ}$
$\mathrm{ASI}$

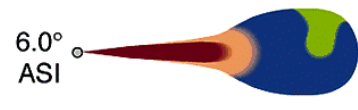

$3.0^{\circ}$

ASI

$6.5^{\circ}$

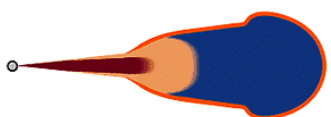

$4.0^{\circ}$

ASI

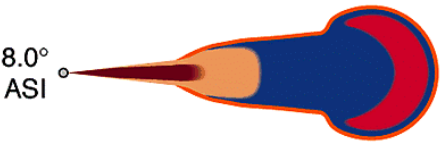

ASI

$10.0^{\circ}$
ASI

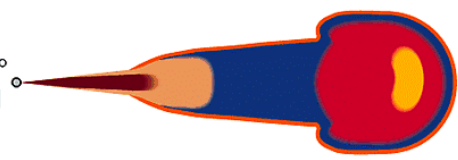

$\stackrel{0 \quad 10 \quad 20}{0 \quad \text { Scale }(\mathrm{mm})}$

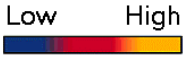

Soot Concentration

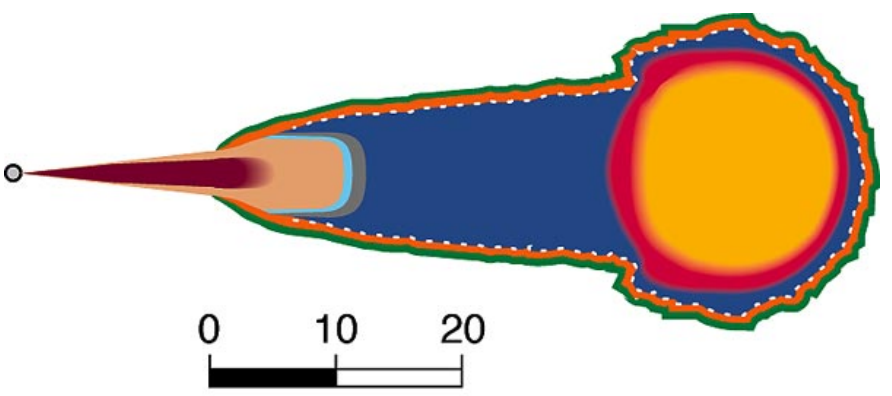

Scale $(\mathrm{mm})$

Fuel-Rich Premixed Flame

Initial Soot Formation

$\square$ Thermal NO Production Zone

Soot Oxidation Zone

Figure 4 Schematic of quasi-steady burning jet from laser measurements.

\section{CHEMICAL KINETIC ANALYSIS}

An additional tool that has proven to be valuable in appraising the combustion of hydrocarbon fuels is detailed chemical kinetic modeling. Kinetic modeling of hydrocarbon fuel oxidation has been developed over the past 25 years, initially for simple fuels such as methane and methanol, proceeding through fuels such as propane and butane, and recently with much more complex fuels such as normal heptane (29) and isooctane (30). The basic features of such models have been reviewed $(31,32)$, and the current status of the basic chemical data used in these models has been recently summarized (33). For this work, a particular kinetic modeling program, the HCT code (34), was used and it has proven extremely useful and productive. However, a number of other modeling programs are available to carry out similar analyses $(23,35)$.

Detailed kinetic models and reaction mechanisms have been valuable in a wide range of practical engine studies. For example, kinetic modeling showed that flame quenching on cold engine walls was not responsible for unburned hydrocarbon (UHC) emissions from conventional spark-ignition engines (36). Modeling also demonstrated why early injection stratified charge engine combustion was likely to lead to high UHC emissions (37). More recently, kinetic modeling has been used to help understand the roles played by fuel molecular size and structure in determining thermal autoignition rates and octane number in spark-ignition engines $(38,21,22)$.

Kinetic modeling has been used to describe the combustion of natural gas and propane and the authors have found this tool to be excellent in describing the rate of energy release for these fuels. In the present work

Figure 3 Schematics of early flame images from laser measurements. 
this approach has been extended to deal with larger fuel molecules typical of diesel combustion. Conventional diesel fuel consists of a complex, ill-defined mixture of hundreds of hydrocarbon species, many of them including more than 10-15 carbon atoms. Furthermore, the exact composition of commercially available diesel fuel varies from day-to-day and from one fuel supply to another. For careful modeling studies, it is necessary to identify a well-characterized fuel that can be used as a surrogate for diesel fuel. The fuel must have reproducible combustion characteristics that are similar to those of diesel fuel.

The number of intermediate species involved in fuel oxidation reaction increases with the complexity of the fuel molecule and, thus, there is an attendant increase in computational times. Increase in the computational times is of the order of "N!" where "N" represents the number of carbon atoms in the original fuel molecules.

To appraise the reaction processes, initial tests were run with iso-octane and normal heptane as fuels. These fuels represented significant variations in fuel structure and behavior. Iso-octane is a relatively high-octane fuel that might be used in a spark-ignition engine, and as such has lower rates of low temperature fuel oxidation and breakdown. Normal heptane, on the other hand, has a relatively high cetane number. Its properties put it on the other end of the scale in terms of low temperature reactivity, with high rates of energy release at low temperatures. Figure 5 presents modeling results obtained, using the HCT code, to define the evolution of reactions in normal heptane.

The process modeled was a constant pressure reaction starting at a temperature of $900 \mathrm{~K}$, a fuel/air equivalence ratio of 4 , and a pressure of 83 bar. These conditions were chosen to be in the approximate range that was measured by the laser diagnostics (24). All reaction diagrams presented in this paper have similar starting conditions. The diagram shows the consumption of the normal heptane fuel molecules and evolution into molecules of smaller size and eventually their partial combustion as a function of time. The lower part of the diagram shows mass fractions of various species as a function of time. The mass fractions are plotted in a cumulative manner, so that the amount of a particular species is represented as the distance between the lower and upper lines around the region containing the species name. Species occurring in significant quantities are identified by name. All other species are grouped into categories according to the carbon number of the compound.

Initially, only fuel, oxygen, and nitrogen are present. After the initial breakdown of the fuel at about 0.03 milliseconds, various short-lived species such as $\mathrm{C7}$ radicals, aldehydes, and hydrogen peroxide are formed and then consumed. At the end of the reaction, the products are seen to be hydrogen, water, carbon dioxide, carbon monoxide, methane, soot precursors, and a few other C3 and C4 compounds.

The upper part of the diagram shows the change in temperature as the mixture evolves through this process of reaction and then finally to a rapid oxidation that consumes all the locally available oxygen. Figure 6 presents a similar set of analyses from identical starting conditions using iso-octane as a fuel. Although the time scales of these reactions are different by a factor of 3 , the actual pattern of reaction intermediates formed and the products of partial combustion that evolve are very similar. Also of note, the temperature at which rapid reactions complete the combustion process is very similar.

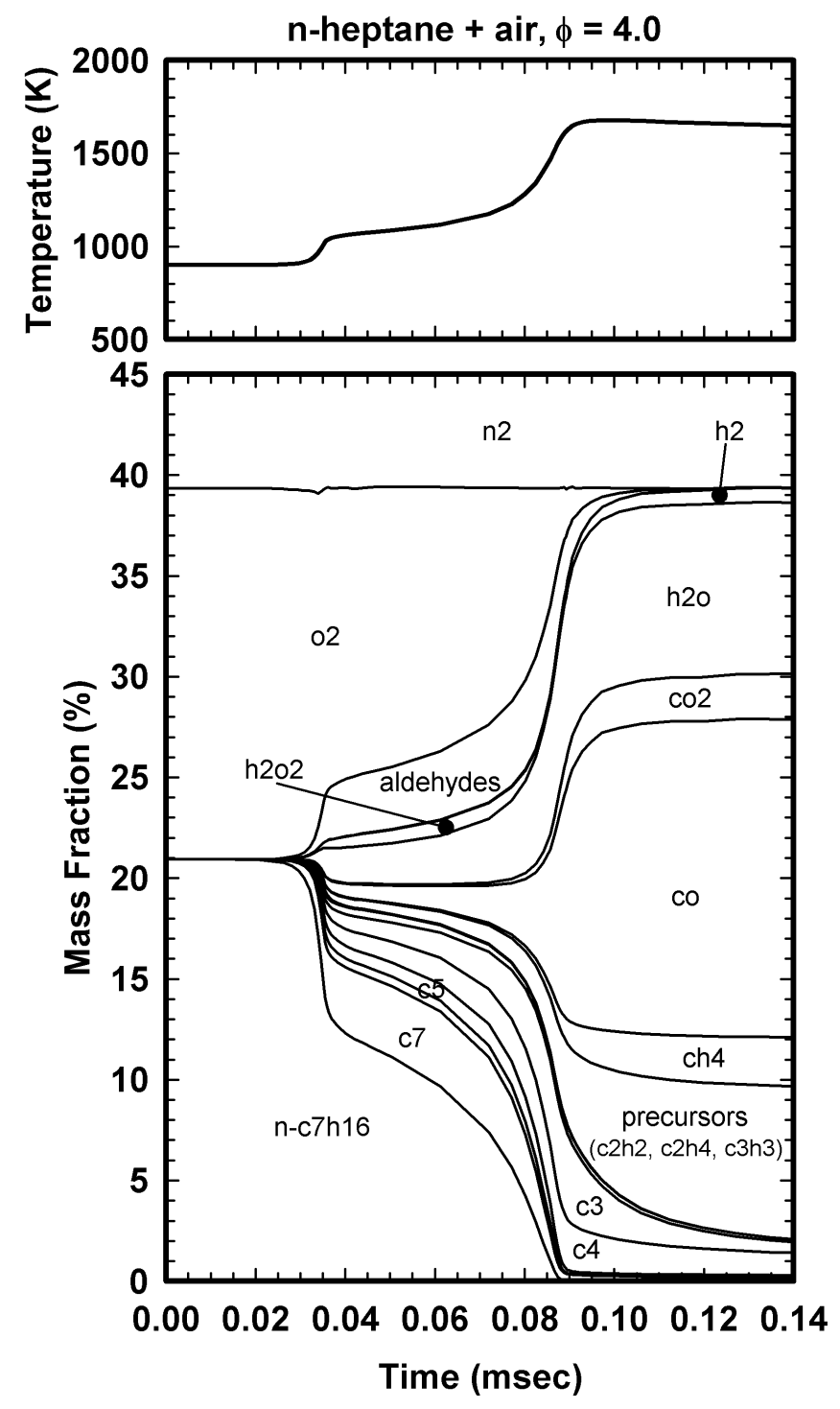

Figure 5. Normal heptane reactions starting at $900 \mathrm{~K}$ and 83 bar.

The computational time on a typical workstation for the run with iso-octane was 7.2 hrs. using 898 species and 
3554 reactions. The computational time for the normal heptane run was $1.6 \mathrm{hrs}$. using 550 species and 2454 reactions. The difference in these times, combined with the similarity in the pattern of product evolution and the similarity in temperatures as these reaction products evolved, prompted the selection of normal heptane as a representative fuel for the analyses that are described in the following sections.
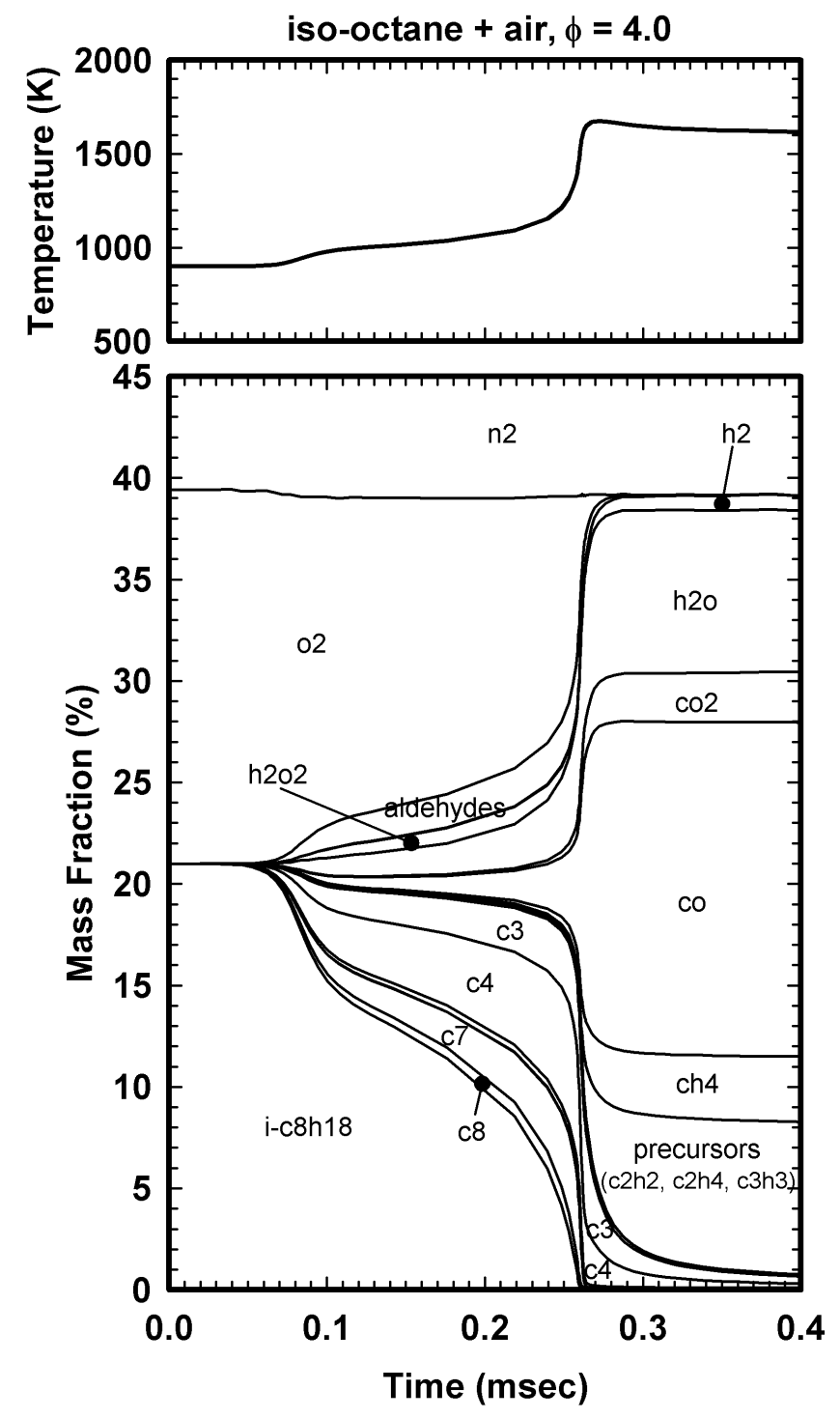

Figure 6 Iso-octane reactions starting at $900 \mathrm{~K}$ and 83 bar.

It is also noteworthy that normal heptane has a cetane rating of 60 , which is closer to that of diesel fuel. In creating the kinetic model that was used in this work, consideration was made of a wide range of experimental conditions, including shock tubes, flow reactors, stirred reactors, spark-ignition engines, laminar flames, and other systems in order to confirm that the model accurately reproduced all of the important features of normal heptane oxidation chemistry. Most important, the kinetics were shown to be reliable under conditions of pressure, temperature, and fuel/air equivalence ratio that are expected during combustion in a modern diesel engine.

Figure 7 presents the results of a series of chemical kinetic analyses with normal heptane. These analyses present the time to fifty percent completion of the energy release process in burning normal heptane at a fuel/air equivalence ratio of one for several temperatures. This plot represents the aggregation of several constant temperature flow reactor calculations. Temperature was held constant by assigning large values of heat transfer to the system. This allowed the characterization of reaction rates on the basis of temperatures and pressures assigned in each case. As can be seen in the figure, reactions at modest rates are initiated at temperatures on the order of $700 \mathrm{~K}$ and the reaction rates increase rapidly as the temperature of the mixture is increased. The rates of reaction that are typified in this diagram can also be related to the requirements of reaction speed that will be required for processes inside engines. At $700 \mathrm{~K}$, reaction time is of the order of several milliseconds which is several times larger than the time scales of engine processes. Reaction times of the order of tenths of milliseconds are required for heat release to reach completion within 30-40 crank angle degrees as required for optimal high-speed engine performance. The rates of reaction shown in Figure 7 are in line with observations of other researchers relative to engine cold starting and ignition of diesel fuel jets in air at varying temperatures. $(39,40)$.

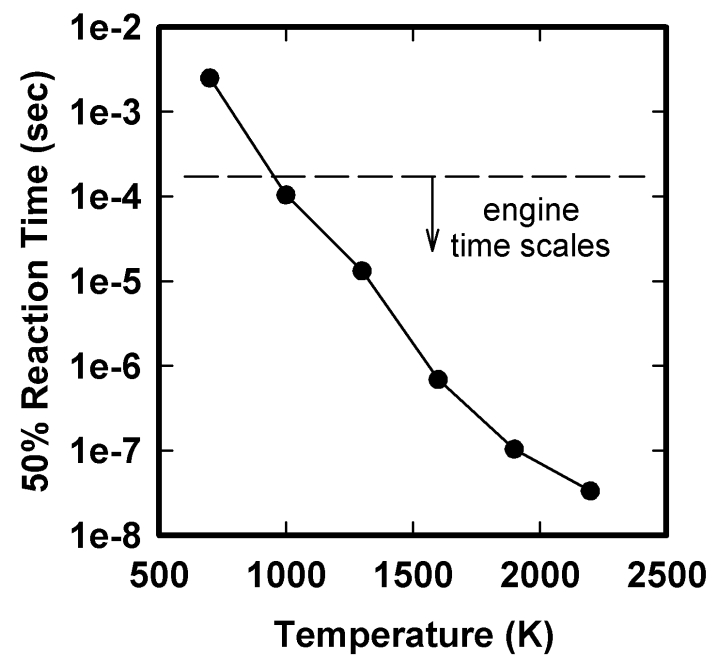

Figure 7 Reaction rates for normal heptane at 150 bar and $\phi=1$.

\section{FUEL/AIR MIXING AND IGNITION}

Parallel to the work by Dec on combustion imaging, Siebers completed a series of high pressure, high temperature jet penetration and vaporization studies at the Combustion Research Facility (11). The results of 
these experiments led to the formulation of models for liquid jet breakup and droplet vaporization in high pressure, high temperature environments like those inside diesel engines.

Figure 8 portrays the key findings from these experiments $(41,42)$. The highlighted zones represent the range of pressure and temperature conditions that might be encountered in a typical heavy-duty turbocharged diesel engine over its entire range of operation from startup to regular operations.

The information presented from these experiments on liquid jets is in close agreement with the measurements made by Dec in the operating engine. Siebers' measurements define the fuel/air concentrations inside the vaporizing spray plume spatially and temporally. The correlation allowed the creation of a function describing the mixing and entrainment processes in noncombusting sprays. Thus a description of the temperatures and fuel/air concentrations as a function of space and time in the plume can be calculated for various injection system parameters and in-cylinder conditions.

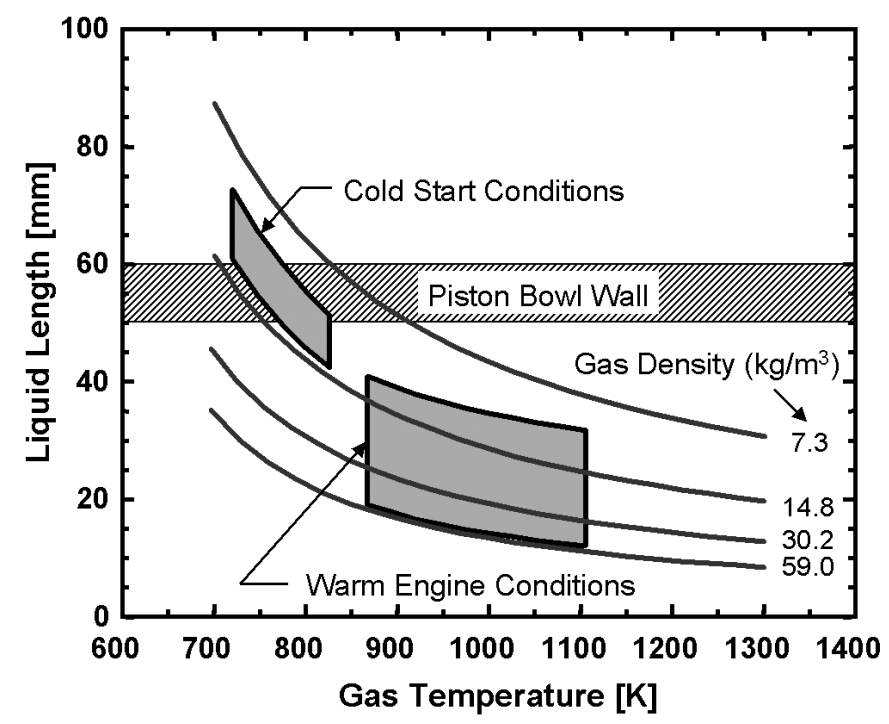

Figure 8 Vaporizing, non-combusting, liquid penetration length measurements for \#2 diesel fuel (42).

Using these descriptions, it is possible to perform a piecewise analysis of the injection, vaporization, and initial reaction processes. This information creates a quantitative context for the concepts depicted in Figure 3. Figure 3 presents the evolution of the vaporizing fuel spray early in the injection process. The pictures start immediately after the beginning of injection and show the development of a liquid jet. As penetration increases, more and more hot air is entrained into the jet, causing its temperature to rise. As the liquid fuel is heated, it vaporizes and a sheath of vaporized heated fuel/air mixture forms around the jet's periphery and at the leading edge of the jet. The vaporizing fuel jet grows until about 5 crank angle degrees (.7 milliseconds) after the start of injection when the temperatures in the plume reach approximately $750 \mathrm{~K}$. At these temperatures, reactions typical of the breakdown of high cetane fuels begin to occur. As these reactions take place and additional hot air is entrained into the jet, temperatures within the jet reach approximately $825 \mathrm{~K}$, increasing the rate of these oxidation reactions.

Analyses indicate that the products of these reactions are largely $\mathrm{C}_{2} \mathrm{H}_{2}, \mathrm{C}_{2} \mathrm{H}_{4}, \mathrm{C}_{3} \mathrm{H}_{3}$ fuel fragments, $\mathrm{CO}$ and $\mathrm{H}_{2} \mathrm{O}$. Most of the energy release in these early reactions arises from the formation of water. The fuel fragments are typical of the elemental building blocks required to form poly-aromatic hydrocarbon structures that lead to soot inside the engine (45-50). The temperatures reached as these reactions occur are of the order of $1600-1700 \mathrm{~K}$. As these reaction products are formed, they are pushed aside by the penetrating jet and then reentrained into the jet. Temperatures within the jet rise, shortening the jet and stabilizing it into a shape similar to that shown in the last frame of Figure 3. In this frame one can clearly see the liquid jet, which is about $25 \mathrm{~mm}$ long and surrounded by a sheath of fuel/air vapor. At about the same time, the diffusion flame begins to form around the jet's periphery. As Figure 3 indicates, starting at about 6.5 crank angle degrees after the start of injection, a diffusion flame sheath forms around the periphery of the cloud of partial oxidation products. These hot oxidation products then become available for aspiration into the entering jet by shear stresses in the zone between 21-30 mm from the nozzle orifice. 

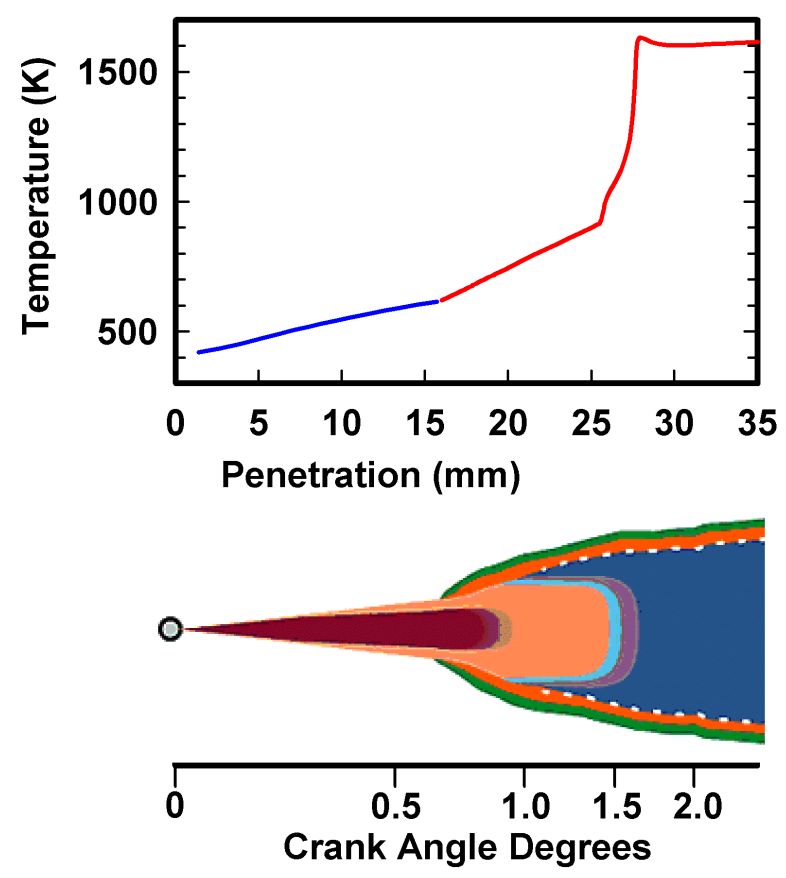

\begin{tabular}{ccc|c|c}
\hline & 0.05 & 0.1 & 0.2 & 0.3 \\
\multicolumn{2}{c}{$\begin{array}{c}1 \\
\text { Time (msec) }\end{array}$} &
\end{tabular}

\begin{tabular}{lllll}
\hline 10 & 10 & 7 & 5 & 4 \\
& Equivalence Ratio
\end{tabular}

Figure 9 Early jet processes.

Figure 9 presents a more detailed picture showing the temperature and spatial properties of this jet after quasisteady processes are established. The figure shows temperatures and penetration for the jet schematic from Figure 4.

The three axes at the bottom of Figure 9 provide additional information about the quasi-steady spray plume. The first axis shows the time required for penetration, given in crank angle degrees, estimated from the jet mixing correlation developed by Siebers (11). The second axis is the same information presented in milliseconds. The third axis shows the mean or average equivalence ratio in the jet as a function of penetration also estimated from the mixing correlation of Siebers.

In the quasi-steady jet, the temperature of the liquid fuel jet rises by mixing with hot air from its injection temperature of $\sim 350 \mathrm{~K}$ to a temperature of $\sim 650 \mathrm{~K}$ before it enters the region surrounded by the diffusion flame sheath. The processes of liquid heating, fuel vaporization, and fuel vapor heating have been depicted using a pseudo specific heat for the entire range of states from liquid at $350 \mathrm{~K}$ to vapor at $650 \mathrm{~K}(43,44)$.
Since no significant chemical changes occur in the fuel, only the energy input required for the change in state is needed to assess the thermodynamic status of the fuel/air mixture. The pseudo specific heat for normal heptane over this temperature range was $878.7 \mathrm{cal} /(\mathrm{kg}$ $\mathrm{K})$. A similar approach has been used to appraise the heating process for fuels entering the combustion chamber for all fuels discussed in the following sections.

Inside the diffusion flame sheath the recirculated products of partial combustion can be entrained in the jet. These hot products of partial combustion increase the temperature rise in the jet per unit length of penetration and temperatures rise quickly to about $825 \mathrm{~K}$ where oxidation reactions can be completed rapidly.

The energy released by the initial low temperature fuel oxidation reactions are sufficient, given the rich stoichiometry of the mixture, to cause the local temperature to rise well above $1150 \mathrm{~K}$. At this temperature threshold, reaction rates increase rapidly leading to the complete consumption of all available oxygen and driving local temperatures to about $1600 \mathrm{~K}$.

\section{PARTICULATE FORMATION}

As indicated earlier, the products from the early reaction zone are small, partially burned fragments of hydrocarbons of $\mathrm{C}_{4}$ or smaller in size with a large portion of the fragments being $\mathrm{C}_{2} \mathrm{H}_{2}, \mathrm{C}_{2} \mathrm{H}_{4}$, and $\mathrm{C}_{3} \mathrm{H}_{3}$. These products of partial combustion are the species generally believed to lead to the formation of the polycyclic aromatic hydrocarbons (PAHs) that are the building blocks for particulates in flames (45-50). The temperature reached by this partial oxidation of fuel is about $1600 \mathrm{~K}$ as stated earlier, and the reaction products will subsequently receive heat diffusing from the hot diffusion flame around the periphery of the reaction zone. This hot oxygen depleted region has chemical constituents that are favorable for the formation and agglomeration of soot particles.

Diagnostics by Dec (18) indicated the appearance of small particulates in the plume near these rich reaction zones. The size of the particulates grew as the mixture progressed downstream inside the spray plume envelope. Because of the complexity of the reaction schemes required to describe the formation and agglomeration of particulates, the authors have invested little analysis time to date on precise definition of the processes within the diffusion flame sheath.

The analysis of the overall chemical kinetics of hydrocarbon oxidation, combined with a knowledge of the constituents entering the interior of the flame, allows speculation on such quantities as local temperatures, local oxygen availability, and the level of energy release that occurs in the several zones of the flame. 


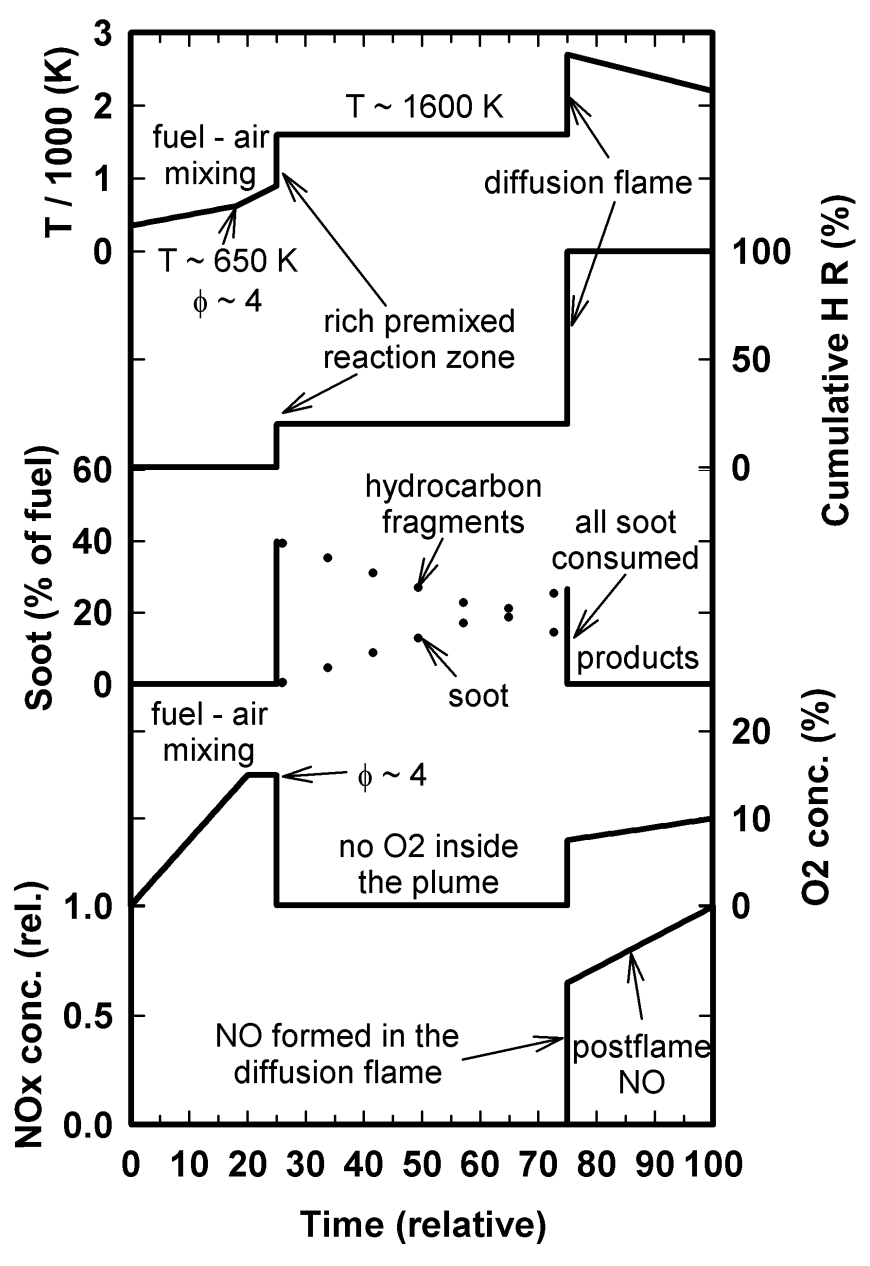

Figure 10 Reaction speculation.
Speculation on the potential sequence of reactions is presented in Figure 10. In the figure, the evolution of temperature, the cumulative heat release, the local oxygen concentration, and particulate and NOx formation are shown. The abscissa on this diagram depicts the time of occurrence of various processes that oxidize the fuel. In the figure, 100 represents total times between .3 and 2 milliseconds. These times correspond to times of flight for a packet of fuel entering the engine from the injector and traveling through the burning spray plume until it is fully consumed.

As the figure indicates, fuel enters the combustion chamber at modest temperatures and is heated by the entrained hot air. The temperature rises gradually until it enters the region surrounded by the diffusion flame sheath at approximately $650 \mathrm{~K}$. No significant energy release takes place at these low temperatures. Therefore the temperature of the fuel/air mixture is defined by the initial temperature of the fuel, the temperature of the surrounding air, and the degree to which the air has been entrained into the jet.

Inside the diffusion flame sheath where the entrained products of combustion and heat transfer from the surroundings can increase the temperature of the mix rapidly, the temperature rise per unit length of travel increases. Within a few millimeters, temperatures of 800-850 $\mathrm{K}$ are reached. At these temperatures, reactions break down the fuel into smaller fragments that are then oxidized. These oxidization reactions consume all locally available oxygen and leave a mixture of $\mathrm{CO}$, $\mathrm{CO}_{2}$, water vapor and fuel fragments at about $1600 \mathrm{~K}$.

As these fuel fragments are transported through the interior of the plume toward the boundary of the diffusion flame sheath, their temperature increases through radiative and convective heat transfer from the flame sheath. At the flame sheath, fuel fragments encounter a very thin reaction zone, where the rest of the heat of combustion is liberated and local temperatures rise above $2500 \mathrm{~K}$. The thinness of the reaction zone follows from Figure 7 , which shows very fast reaction at temperatures above $2000 \mathrm{~K}$.

Observing the degree of reaction as indicated by the cumulative heat release from the fuel as it progresses along this path, the chemical analysis indicates that within the rich reaction zone 10-15 percent of the heat of combustion is liberated. At the diffusion flame interface, the rest of the chemical energy in the fuel is released.

Regarding the formation of particulates, it is speculated that only fuel molecules exist as the fuel progresses into the burning plume. These fuel molecules might pyrolyze and form carbonaceous materials if afforded long residence times. But, the reactions occurring at these temperatures would be very slow and produce forms of carbon that are not typically found in diesel soot. 
As the fuel passes through the rich premixed reaction zone, the process yields hydrocarbon fragments that become the building blocks of soot particles inside the diffusion flame sheath. As indicated earlier in the discussions on chemical kinetics, the small fuel fragments appear to be the ideal elemental building blocks for soot particle formation, although no diagnostics or data are available to indicate the yield of particulates from these initial constituents. Laser diagnostics indicate that precursors originally form small particulates and as they travel down the plume they agglomerate and react to form the larger particulates of the kind emitted from the engine's tail pipe. A variety of experiments also show that these particulates are completely consumed by the hot diffusion flame sheath while high heat release rates persist (51). Diesel soot emissions appear to be the result of quenching this final phase of oxidation.

Plotting the oxygen concentration that might be observed within the plume, the fuel starts as a liquid with no oxygen. Oxygen molecules are gradually entrained with the air until the fuel enters the diffusion flame sheath. Once inside the diffusion flame sheath, the fuel/air ratio, or more appropriately the fuel/oxygen ratio, is fixed and eventually the fuel passes through the rich reaction zone where all local free oxygen is consumed. Inside the plume, virtually all oxygen is found in the form of products, such as $\mathrm{H}_{2} \mathrm{O}, \mathrm{CO}$, and $\mathrm{CO}_{2}$. As the fuel fragments approach the diffusion flame, they become hotter and are oxidized completely by oxygen diffusion into the burning flame from the exterior of the flame sheath.

Figure 11 provides a more detailed speculation about the processes that might quantify the production and destruction of soot and its precursors within the flame as the combustion process evolves. These data are typical of combustion conditions in a 2.35 liter per cylinder heavy-duty diesel engine operating at high load. Likewise the cylinder pressure is typical of that observed at an engine output of 17.2 bar BMEP and a speed of $1800 \mathrm{rpm}$. The second line represents the rate of fuel injection at that operating point. The next series of lines present a depiction of apparent heat release for this operating condition.

The apparent heat release diagram has two parts. The lower shaded portion of the diagram is a depiction of the energy release associated with the early premixed fuel burn. This energy is released from fuel molecules as they pass through the rich reaction zone and enter the interior of the burning spray plume. The area above this shaded portion represents the remainder of the energy release that occurs at the diffusion flame interface.

Thus, it is speculated that energy release from fuel in a diesel engine is a two-stage process. The next lines speculate about the soot and soot precursor formation and destruction rates that occur during this two-stage combustion process.

The solid line showing soot precursor production rate in Figure 11 assumes that during the heat release process of the initial premix burn, the soot precursor formation rate is such that 45 percent of the fuel is partially oxidized into fuel fragments that are the building blocks for particulates. The dashed trace in the diagram represents the rate of particulate and precursor oxidation at the diffusion flame sheath. It is assumed that all the precursors and the particulates formed are oxidized in the diffusion flame. Speculating about a precursor and particulate mass inside the chamber is now possible using the net difference in these formation and destruction rates,

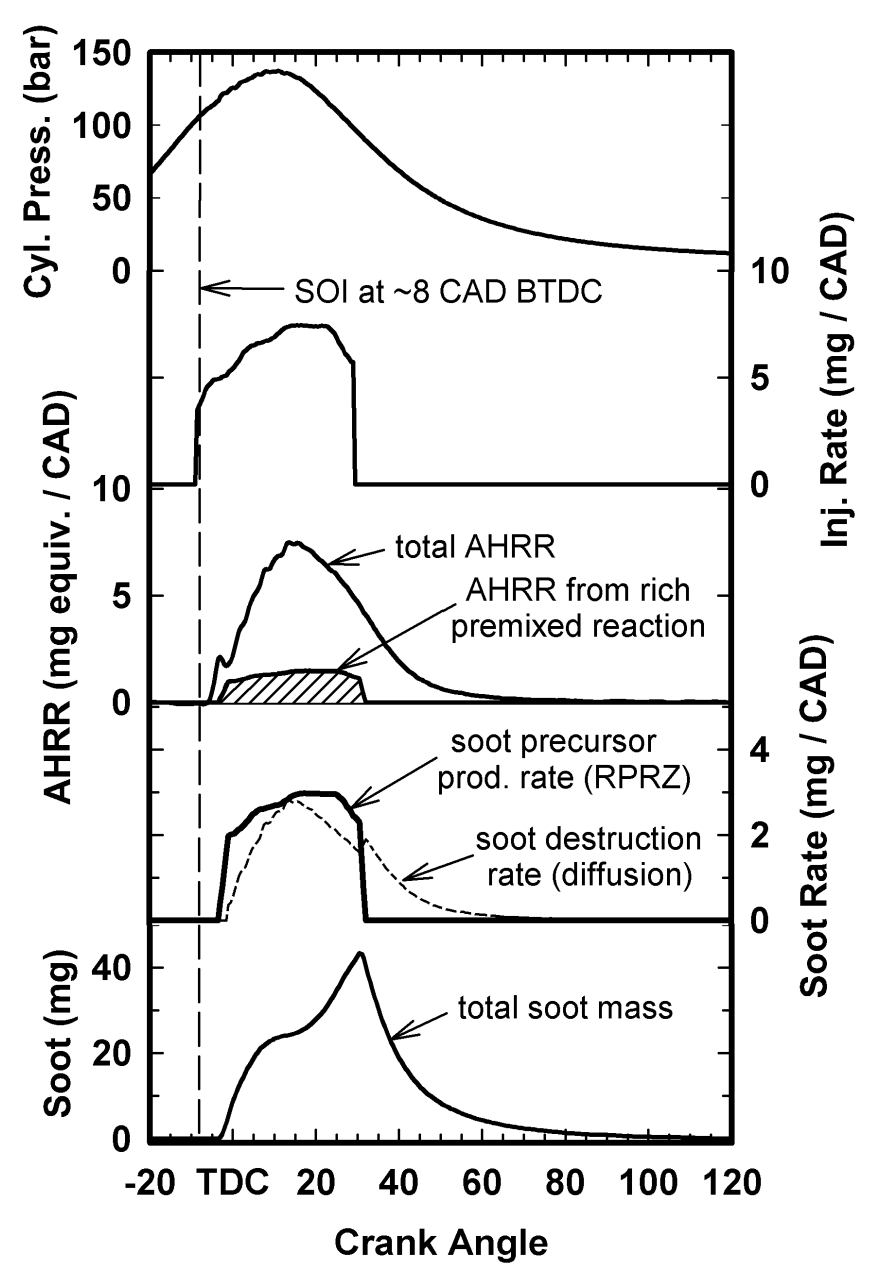

Figure 11 Hypothetical soot formation and destruction processes.

The total soot mass line in Figure 11 represents an estimate of the limiting mass that could exist in the chamber at any given time.

This test run used 240 milligrams of fuel per individual cycle. Thus, the 30-45 milligrams of soot that are indicated as possible maximum amounts in the chamber 
represent an emissions rate of over 125 grams of soot per kilogram of fuel burned. This would convert to approximately $20 \mathrm{gm} / \mathrm{BHP}-\mathrm{Hr}$ if emitted from the tail pipe. This value is 200 times the allowed particulate emissions rates from this engine.

As stated earlier, precise analysis of the relative yield of soot particles from precursors is beyond the authors' present capability. There has been no precise determination of the actual soot and soot precursors present in the cylinder for various times during the cycle. However, it is very clear that the circumstances created within the spray plume provide precisely the constituents, temperatures, pressures, and oxygen availability that are understood to be favorable for particulate formation.

\section{EFFECT OF OXYGENATED FUELS}

Several researchers have presented information about the variation in particulate emissions when oxygenated fuels are used in diesel engines.

In 1998 researchers showed that when the oxygen content of the supplied fuel is raised to approximately 30 percent by mass that exhaust tail pipe particulate emissions completely disappeared (52) as shown in upper portion of Figure 12.

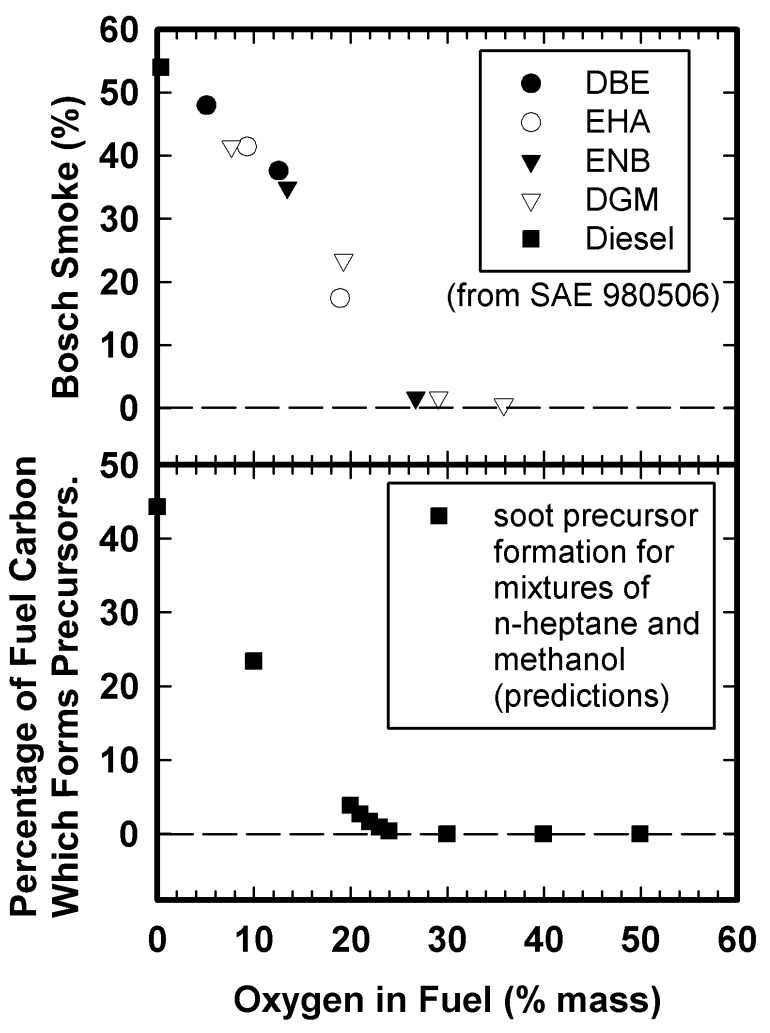

Figure 12 Smoke emissions and particulate precursor formation rates (52).
In the case where oxygenated fuel molecules are supplied, we chose to apply the analysis as outlined by Siebers (11). This analysis, shown in the lower portion of Figure 12, used normal heptane and methanol mixtures to vary the oxygen content of the incoming fuel. The analysis includes an appraisal of the specific heats of the fuels, the variations in the heat of vaporization of the fuels, and again the mixing rates as outlined by Siebers. The pseudo specific heat used for methanol is $1279.9 \mathrm{cal} /(\mathrm{kg}-\mathrm{K})$. As the mass fraction of oxygen in the fuel mixture increases, a larger fraction of the carbon can be converted to CO. Thus, a smaller fraction of the carbon is available to form particulate precursors.

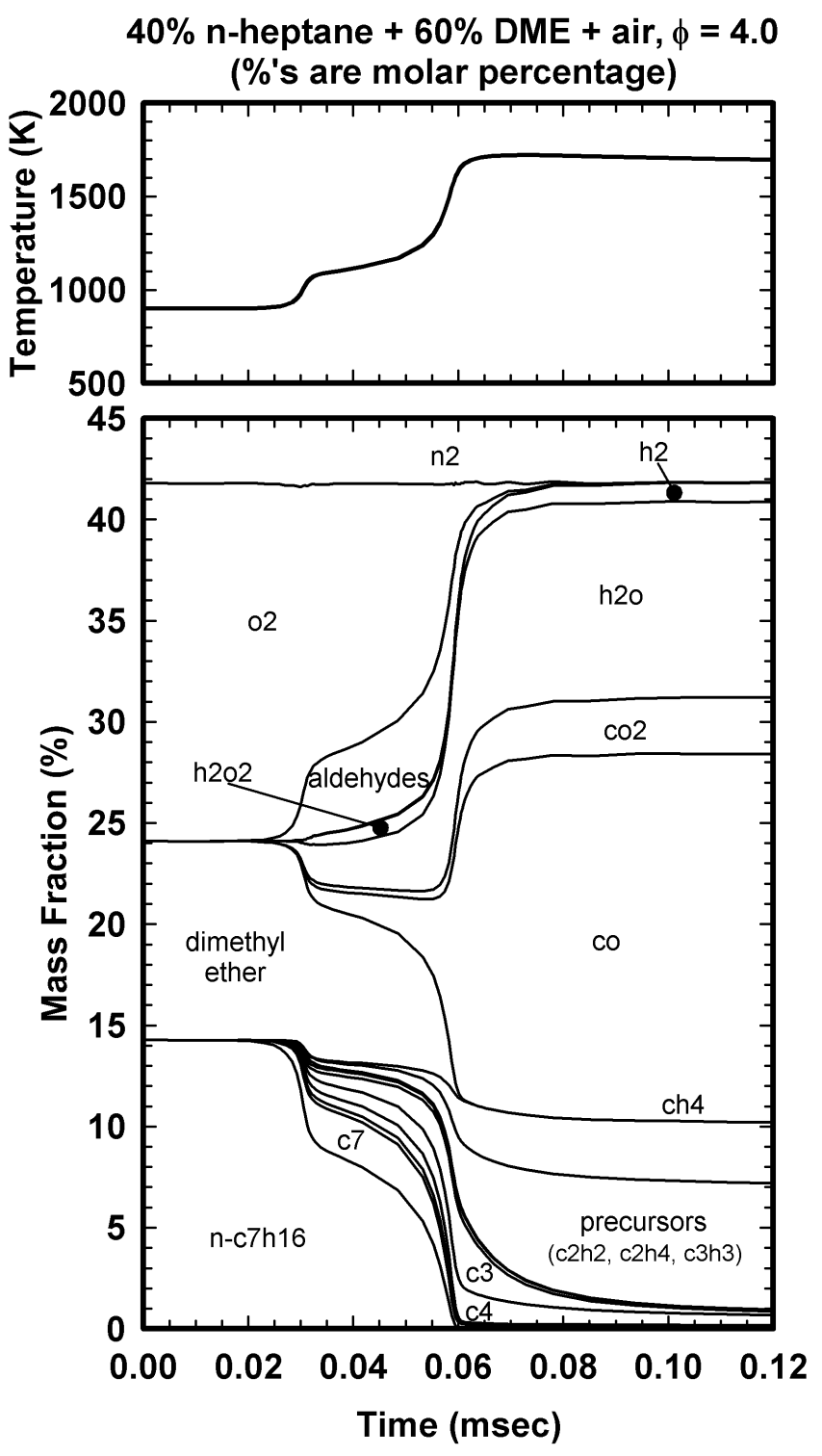

Figure 13 Oxygenated fuel reactions starting at $900 \mathrm{~K}$ and 83 bar.

Figure 13 portrays particulate precursor formation in a mixture of dimethyl ether and normal heptane. The 
pseudo specific heat used for dimethyl ether was 802 $\mathrm{cal} /(\mathrm{kg}-\mathrm{K})$. This diagram, like Figure 5 , shows a distribution of carbon atoms as they would pass through the initial rich premixed reaction zone. The oxygen in the entrained air combined with that available in the fuel provides a leaner mixture at the critical temperatures of 800-850 K where significant energy release begins. This provides more oxygen and thus more $\mathrm{CO}$ formation than for a pure hydrocarbon fuel with no oxygen. As the diagram indicates, this results in much smaller amounts of $\mathrm{C}_{2} \mathrm{H}_{2}, \mathrm{C}_{2} \mathrm{H}_{4}$, and $\mathrm{C}_{3} \mathrm{H}_{3}$ formation, along with a larger portion of the carbon leaving the rich premixed zone as CO.

These analyses indicate that the potential for particulate precursor formation disappears almost completely at an oxygen-to-fuel mass ratio of 25 percent.

This disappearance of precursor formation agrees closely to the data presented by Miyamoto (52) for their various mixtures of oxygen bearing compounds and fuel.

Figure 14 presents a comparison of the analytical results shown previously with those obtained from a similar analysis using normal heptane, dimethyl ether (DME) blends. In this diagram it is easy to see that for both of these oxygenates, the soot precursors disappear and hence the potential for particulate formation goes to zero at an oxygen-to-carbon atom ratio of 1.5 in the supplied air fuel mix. With the introduction of oxygenates with the incoming fuel, the fuel/air in the rich premixed burn decreases. Thus, the potential for the formation of soot precursors decreases while the formation of more complete products of combustion increases.

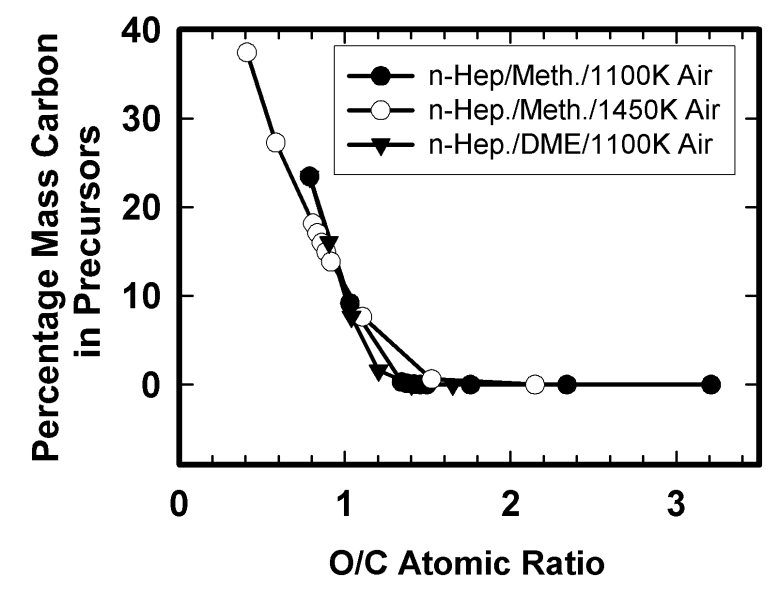

Figure 14 Particulate precursor process yield with oxygenate fuel mixtures.

\section{$\mathrm{NO}_{\mathrm{x}}$ FORMATION}

Several researchers have provided data on the evolution of NOx formation as a function of time inside engines.
"Dumping" experiments indicate that most of the NOx formation takes place during the time of high-energy release rates associated with the diffusion burning process in the diesel engine. In Dec's measurements, NOx is observed initially in a relatively thin sheath surrounding the exterior of the diffusion-burning interface. Here the diffusion-burning interface is identified by the existence of a thin layer of $\mathrm{OH}$ fluorescence. This $\mathrm{OH}$ fluorescence layer is believed to identify the key reaction intermediary required for completion of the oxidation reactions in the fuel fragments and particulates.

Data from Dec's analysis (25) and from previously documented measurements on apparent flame temperatures (51) in these diffusion burning processes indicate that the sheath of the diffusion flame presents the conditions ideal for the formation of NOx. That is, high temperatures in a region where oxygen is available along with nitrogen to allow the formation of nitrogen oxides. Once NOx has been formed, it can diffuse both into and away from the diffusion flame sheath. Figure 15 presents a hypothetical picture of the evolution of the NOx concentration inside the same engine presented earlier in the section on particulate formation and consumption. As was stated earlier, this operating point is $1800 \mathrm{rpm}$ and 17.2 bar BMEP. Dec's data indicate that about 65 percent of the tail pipe NOx is created during the vigorous portion of heat release and approximately one-third of the NOx is formed as hot products of combustion mix out during the expansion process. This picture is somewhat different than the pattern of NOx formation presented from the results of dumping experiments (53).

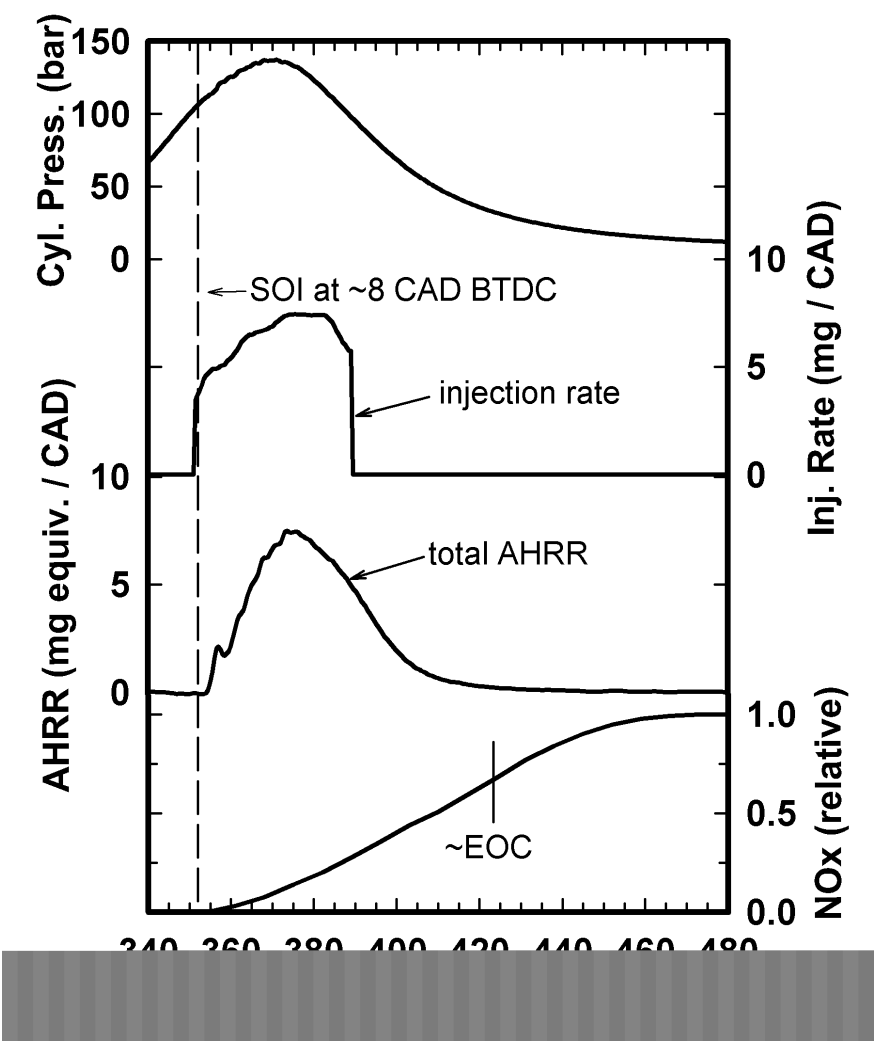


Figure 15 Pattern of NOx formation during combustion.

\section{OVERVIEW}

Figure 16 provides an integrated perspective of the thermal and chemical variations inside the burning fuel plume. The key attributes of the process are the existence of a cold fuel jet into which hot air is entrained. This fuel/air mixture enters a diffusion flame sheath where it is further heated to about $825 \mathrm{~K}$ and reactions are initiated which consume all the local oxygen and release about 15 percent of the total heat of combustion. This jet thus supplies the interior of the plume with products of rich combustion that contain mostly carbon monoxide and partially-burned hydrocarbons that are the building blocks of particulates.

Surrounding the burning plume, a thin diffusion flame is formed where complete oxidation occurs yielding the products of complete combustion. In this diffusion flame, fuel fragments and particulates are converted to $\mathrm{CO}_{2}$ and water vapor. Temperatures at the diffusion flame interface are high, providing an ideal environment for NOx formation reactions. Thus, the process can be thought of as cold liquid fuel entraining warm air supplying the reactants for a rich premixed reaction feeding the interior of the plume. These products of rich combustion are then oxidized at the diffusion flame surface. It appears that no free oxygen is available inside the diffusion flame sheath and that the constituents and temperatures existing inside the sheath are ideal for the formation of diesel particulate.

\section{Temperatures}

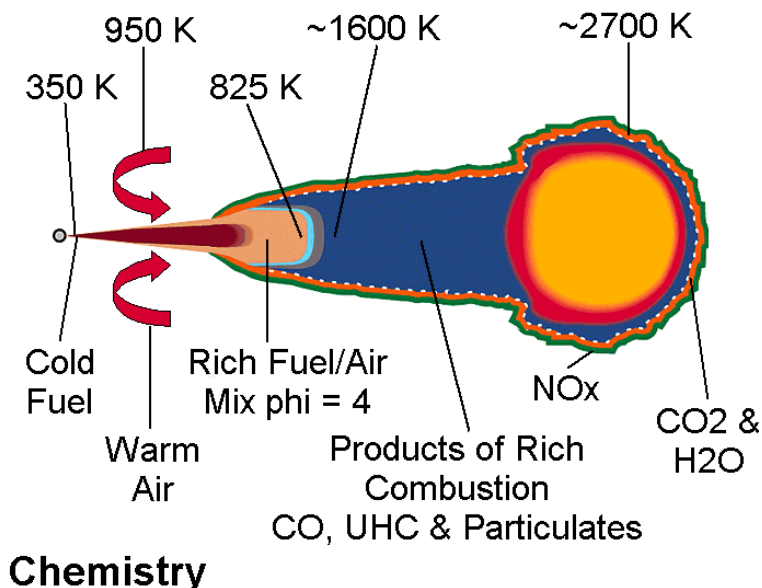

Figure 16 Summary of fuel burning processes.
Through a combination of laser diagnostics, empirical measurements, and piecewise analyses with chemical kinetic codes, a beginning understanding of the processes occurring in diesel combustion has evolved. The processes appear to support quantitatively and qualitatively the reaction schemes hypothesized by Dec in his 1997 paper. Very rich fuel/air mixtures enter the interior of the diffusion flame. The flame has a definite interior and exterior. The products of rich combustion supply the species that cause particulate formation in the interior. These particulates are burned as they approach the high temperature diffusion flame around the periphery of the burning plume.

If continuing progress is to be made in the understanding of burning diesel fuel spray plumes, it appears the processes outlined here must be modeled in more detail. In particular, the elements that should be included are:

1. The complete disappearance of fuel droplets in approximately $22-27$ millimeters.

2. The rich premixed reaction zone which forms the particulate precursors.

3. The hot oxygen depleted zone where these particulate precursors can agglomerate and form particulates.

4. The thin diffusion flame around the periphery of the plume in which the fuel fragments are completely consumed and the energy supplied to the local environment fixes NOx.

We would encourage colleagues to do additional piecewise modeling and further experimental investigations of these processes to gain more detailed quantitative understandings of the entire set of linked processes.

\section{ACKNOWLEDGEMENTS}

The authors would like to acknowledge the contributions of many people who have provided valuable ideas and feedback during the development of the information presented in this paper. Dennis Siebers developed the jet mixing model and assisted in its use. Bill Pitz, Henry Curran, and Nick Marinov developed the mechanisms used for the chemistry modeling work. Colleagues at Cummins Engine Company provided empirical data and critical perspectives that helped in understanding the processes analyzed.

This work was performed at Cummins Engine Company, the Combustion Research Facility of Sandia National Laboratories, and Lawrence Livermore National Laboratories.

The authors thank the U. S. Department of Energy's, Defense Programs Technology Transfer Initiative, and

\section{CONCLUSIONS}


Office of Transportation Technologies, along with Cummins Engine Company for supporting this work.

Portions of this work were carried out under the auspices of the US Department of Energy by the Lawrence Livermore National Laboratory under contract W-7405ENG-48.

\section{NOMENCLATURE}

$\begin{array}{ll}\text { AHRR } & \text { apparent heat release rate } \\ \text { ASI } & \text { after start of injection } \\ \text { ATDC } & \text { after top dead center } \\ \text { BMEP } & \text { brake mean effective pressure } \\ \text { BTDC } & \text { before top dead center } \\ \text { CAD } & \text { crank angle degrees } \\ \text { EOC } & \text { end of combustion } \\ \text { LII } & \text { laser induced incandescence } \\ \text { PAH } & \text { poly-aromatic hydrocarbon } \\ \text { PLIF } & \text { planar laser-induced fluorescence } \\ \text { RPRZ } & \text { rich premixed reaction zone } \\ \text { SOC } & \text { start of combustion } \\ \text { SOI } & \text { start of injection } \\ \text { TDC } & \text { top dead center } \\ \text { UHC } & \text { unburned hydrocarbon } \\ \phi & \text { fuel / air equivalence ratio }\end{array}$

\section{REFERENCES}

1. zur Loye, A. O., Siebers, D. L., and Dec, J. E., "2-D Soot Imaging In A Direct-Injection Diesel Engine Using LaserInduced Incandescence," Proceedings of the International Symposium on Diagnostics and Modeling of Combustion in Internal Combustion Engines, COMODIA 90, pp. 523528, 1990.

2. Dec, J. E., zur Loye, A. O., and Siebers, D. L., "Soot Distribution In A D.I. Diesel Engine Using 2-D LaserInduced Incandescence Imaging," SAE Transactions, vol. 100, sec. 3, pp. 277-288, SAE 910224, 1991.

3. Espey, C., and Dec., J. E., "Diesel Engine Combustion Studies In A Newly Designed Optical-Access Engine Using High-Speed Visualization And 2-D Laser Imaging," SAE Transactions, vol. 102, sec. 4, pp. 703-723, SAE 930971, 1993.

4. Dec., J. E. and Coy, E. B., "OH Radical Imaging In A D.I. Diesel Engine And The Structure Of The Early Diffusion Flame," SAE 960831, 1996.

5. Lee, W., Solbrig, C. E., Litzinger, T. A., Santoro, R. J., and Santavicca, D. A., "Planar Laser Light Scattering For The In-Cylinder Study Of Soot In A Diesel Engine," $S A E$ Transactions, vol. 99, sec. 3, pp. 2222-2235, SAE 902125, 1990.

6. Alatas, B., Pinson, J. A., Litzinger, T. A., and Santavicca, D. A., "A Study Of NO And Soot Evolution In A D.I. Diesel Engine Via Planar Imaging," SAE Transactions, vol. 102, sec. 3, pp. 1463-1473, SAE 930973, 1993.

7. Pinson, J. A., Ni, T., and Litzinger, T. A., "Quantitative Imaging Study Of The Effects Of Intake Air Temperature
On Soot Evolution In An Optically Accessible D.I. Diesel Engine," SAE 942044, 1994.

8. Hodges, J. T., Baritaude, T. A., and Heinze, T. A., "Planar Liquid And Gas Fuel And Droplet Size Visualization In A D.I. Diesel Engine," SAE Transactions, vol. 100, sec. 3, pp. 1284-1302, SAE 910726, 1991.

9. Baritaud, T. A., Heinze, T. A., and Le Coz, J. F., "Spray And Self-Ignition Visualization In A D.I. Diesel Engine," SAE Transactions, vol. 103, sec. 3, pp. 1129-1144, SAE 940681, 1994.

10. Arnold, A., Dinkelacker, F., Heitzmann, T., Monkhouse, P., Schäfer, M., Sick, V., and Wolfrum, J., "D.I. Diesel Engine Combustion Visualized By Combined Laser Techniques," Twenty-Fourth Symposium (International) on Combustion, pp. 1605-1612, 1992.

11. Naber, J. D., and Siebers, D. L., "Effects Of Gas Density And Vaporization On Penetration And Dispersion Of Diesel Sprays," SAE 960034, 1996.

12. Wiltafsky, G., Stolz, W., Köhler, J., and Epsey C., "The Quantification Of Laser-Induced Incandescence (LII) For Planar Time Resolved Measurements Of The Soot Volume Fraction In A Combustion Diesel Jet," SAE 961200, 1996.

13. Epsey, C. and Dec., J. E., "The Effect Of TDC Temperature And Density On The Liquid-Phase Fuel Penetration In A D.I. Diesel Engine," SAE Transactions, vol. 104, sec. 4, pp. 1400-1414, SAE 952456, 1995.

14. Epsey, C., Dec, J. E. Litzinger, T. A., and Santavicca, D. A., "Quantitative 2-D Fuel Vapor Concentration Imaging In A Firing D.I. Diesel Engine Using Planar Laser-Induced Rayleigh Scattering," SAE Transactions, vol. 103, sec. 3, pp. 1145-1160, SAE 940682, 1994.

15. Epsey, C., Dec, J. E., Litzinger, T. A., and Santavicca, D. A., "Planar Laser Rayleigh Scattering For Quantitative Vapor-Fuel Imaging In A Diesel Jet," Combustion and Flame, vol. 109, pp. 65-86, 1997.

16. Dec, J. E. and Epsey, C., "Soot And Fuel Distributions In A D.I. Diesel Engine Via 2-D Imaging," SAE Transactions, vol. 101, sec. 4, pp. 1642-1651, SAE 922307, 1992.

17. Dec, J. E., "Soot Distribution In A D.I. Diesel Engine Using 2-D Imaging Of Laser-Induced Incandescence, Elastic Scattering, And Flame Luminosity," SAE Transactions, vol. 101, sec. 4, pp. 101-112, SAE 920115, 1992.

18. Dec, J. E. and Epsey, C., "Ignition And Early Soot Formation In A D.I. Diesel Engine Using Multiple 2-D Imaging Diagnostics," SAE Transactions, vol. 104, sec. 3, pp. 853-875, SAE 950456, 1995.

19. Dec, J. E. and Epsey, C., "Soot And Liquid-Phase Fuel Distributions In A Newly Designed Optically Accessible D.I. Diesel Engine," Proceedings of the 1993 Diesel Emission Reduction Workshop, La Jolla, CA, July 1993.

20. Pinson, J. A., Mitchell, D. L., Santoro, R. J., and Litzinger, T. A., "Quantitative, Planar Soot Measurements In A D.I. Diesel Engine Using Laser-Induced Incandescence And Light Scattering," SAE 932650, 1993.

21. Curran, H. J., Gaffuri, P., Pitz, W. J., Westbrook, C. K., and Leppard, W. R., "Autoignition Chemistry Of The Hexane Isomers: An Experimental And Kinetic Modeling Study," SAE 952406, 1995.

22. Curran, H. J., Gaffuri, P., Pitz, W. J., Westbrook, C. K., and Leppard, W. R. "Autoignition Chemistry In A Motored Engine: An Experimental And Kinetic Modeling Study," Twenty-Sixth Symposium (International) on Combustion, pp. 2669-2677, The Combustion Institute, Pittsburgh, 1996.

23. Kee, R. J., Rupley, F. M., Meeks, E. E., Miller, J. A., "Chemkin-III: A Fortran Chemical Kinetics Package For The Analysis Of Gas Phase Chemical And Plasma Kinetics," Sandia National Laboratories Report, SAND968216, May 1996.

24. Dec, J. E., "A Conceptual Model Of DI Diesel Combustion Based On Laser-Sheet Imaging," SAE 970873, 1997. 
25. Dec, J. E. and Canaan, R. E., "PLIF Imaging Of NO Formation In A D.I. Diesel Engine," SAE 980147, 1998.

26. Dec. J. E. and Espey, C. "Chemiluminescence Imaging Of Autoigntion In A D.I. Diesel Engine," SAE 982685, 1998.

27. Chiu, W. S., Shahed, S. M., and Lyn, W. T., "A Transient Spray Mixing Model For Diesel Combustion," $S A E$ Transactions, vol. 85, pp. 502-512, SAE 760128, 1976.

28. Ricart, L. M., "An Experimental And Computational Study Of Fuel Injection, Mixing And Combustion In Diesel Engines," Ph.D. diss., Mechanical Engineering, University of Wisconsin-Madison, 1998.

29. Curran, H. J., Gaffuri, P., Pitz, W. J., and Westbrook, C. K. "A Comprehensive Modeling Study Of N-Heptane Oxidation," Combustion and Flame, vol. 114, pp. 149-177, 1998.

30. Curran, H. J., Gaffuri, P., Pitz, W. J., and Westbrook, C. K. "A Comprehensive Modeling Study Of Iso-Octane Oxidation," submitted for publication, 1998.

31. Westbrook, C. K., and Dryer, F. L., "Chemical Kinetics And Modeling Of Combustion Processes," Eighteenth International Symposium on Combustion, pp. 749-767, The Combustion Institute, Pittsburgh, 1981.

32. Westbrook, C. K., and Dryer, F. L., "Chemical Kinetics Modeling Of Hydrocarbon Combustion," Progress in Energy and Combustion Science, vol. 10, pp. 1-57, 1984.

33. Warnatz, J., Combustion Chemistry II, W. C. Gardiner, Jr., Springer-Verlag, New York, 1997.

34. Lund, C. M., "HCT - A General Computer Program For Calculating Time-Dependent Phenomena Involving OneDimensional Hydrodynamics, Transport, And Detailed Chemical Kinetics," Lawrence Livermore National Laboratory Report UCRL-52504, 1978.

35. Bowman, C. T., Hanson, R. K., Davidson, D. F., Gardiner, W. C. Jr., Lissianski, V., Smith, G. P., Golden, D. M., Frenklach, M., and Goldenberg, M., http://www.me.berkeley.edu/gri_mech/, sponsored by the Gas Research Institute.

36. Westbrook, C. K., Adamczyk, A. A., and Lavoie, G. A. "A Numerical Study Of Laminar Flame Wall Quenching," Combustion and Flame, vol. 40, pp. 81-99, 1981.

37. Westbrook, C. K.. "Fuel Motion And Pollutant Formation In Stratified Charge Combustion," SAE 790248, 1979.

38. Westbrook, C. K., Pitz, W. J., and Leppard, W. R. "The Autoignition Chemistry Of Paraffinic Fuels And Pro-Knock And Anti-Knock Additives: A Detailed Chemical Kinetic Study," SAE 912314, 1991.

39. Yassine, M. K., Tagomori, M. K., Henein, N. A., Bryzik, W., "White Smoke Emissions Under Cold Starting Of Diesel Engines," SAE 960249, 1996.

40. Parker, T. E., Forsha, M. D., Stewart, H. E., Hom, K., Sawyer, R. F., and Oppenheim, A. K., "Induction Period For Ignition Of Fuel Sprays At High Temperatures And Pressures," SAE 850087, 1985.

41. Edwards, C. F., Siebers, D. L., and Hoskin, D. H., "A Study Of The Autoignition Process Of A Diesel Spray Via High Speed Visualization," SAE Transactions, vol. 101, sec. 3, pp. 187-204, SAE 920108, 1992.

42. Siebers, D. L., "Scaling Liquid-Phase Fuel Penetration In Diesel Sprays Based On Mixing Limited Vaporization," to be presented at 1999 SAE Congress.

43. Turns, S. R., An Introduction To Combustion, McGraw-Hill, Inc., New York, 1996.

44. Westbrook, C. K., and Chase, L. K., "Chemical Kinetics and Thermochemical Data for Combustion Applications," Lawrence Livermore National Laboratories Report UCID17833, 1988.

45. Marinov, N. M., Pitz, W. J., Westbrook, C. K., Vincitore, A. M., Castaldi, M. J., Senkan, S. M., and Melius, C. F., "Aromatic And Polycyclic Aromatic Hydrocarbon Formation In A Laminar Premixed N-Butane Flame," Combustion and Flame, vol. 114, pp. 192-213, 1998.
46. Wagner, H. G., "Soot Formation - An Overview," pp. 1-29, Particulate Carbon Formation During Combustion, D.C. Siegla and G.W. Smith, Plenum Press, New York, 1981.

47. Frenklach, M., Yuan, T., and Ramachandra, M. K., "Soot Formation In Binary Hydrocarbon Mixtures," Journal of Energy \& Fuels, vol. 2, pp. 462, 1988.

48. Markatou, P., Wang, H., and Frenklach, M., "A Computational Study Of Sooting Limits In Laminar Premixed Flames Of Ethane, Ethylene, And Acetylene," Combustion and Flame, vol. 93, pp. 467-482, 1993.

49. Frenklach, M. and Wang, H., "Detailed Modeling Of Soot Particle Nucleation And Growth," Twenty-Third Symposium (International) on Combustion, pp. 1559-1566 The Combustion Institute, 1990.

50. Yoshihara, Y., Kazakov, A., Wang, H., and Frenklach, M., "Reduced Mechanism Of Soot Formation - Application To Natural Gas-Fueled Diesel Combustion," Twenty-Fifth Symposium (International) on Combustion, The Combustion Institute, 1994.

51. Flynn, P. F., "An Experimental Determination Of The Instantaneous Potential Radiant Heat Transfer Within An Operating Diesel Engine," Ph.D., diss., Mechanical Engineering, University of Wisconsin-Madison, 1971.

52. Miyamoto, N., Ogawa, H., Nurun, N. M., Obata, K., Arima, T., "Smokeless, Low NOx, High Thermal Efficiency, And Low Noise Diesel Combustion With Oxygenated Agents As Main Fuel," SAE 980506, 1998

53. Donahue, R. J., Borman, G. L., and Bower, G. R., "Cylinder-Averaged Histories Of Nitrogen Oxide In A D.I. Diesel With Simulated Turbocharging," Fuels \& Lubricants Meeting \& Exposition, October 17-20, 1994, SAE 942046, 1994. 